\title{
IDENTIFICAÇÃO DE PERIÓDICOS DE ARTES EM ACERVO DE BIBLIOTECAS INSTITUCIONAIS BRASILEIRAS
}

\section{Viviane Rummler da Silva Guido Rummler}

\section{Resumo:}

Possivelmente, tanto no âmbito do estudo, do ensino, da pesquisa, como da simples busca de informações sobre artes, há interesse de saber sobre periódicos especializados nesse campo. Com o objetivo de identificá-los, foi desenvolvida uma pesquisa, utilizando como fonte de informação o Catálogo Coletivo Nacional de Publicações Seriadas - CCN. Como resultado da mesma, apresenta-se uma relação dos periódicos referentes aos idiomas português, espanhol, inglês, francês, italiano, alemão e holandês, que possuem algum fascículo editado no ano 2000 e/ou anos subseqüentes em acervo de alguma das bibliotecas nacionais informantes do sistema. Além dos títulos dos periódicos, e respectivos ISSN, são fornecidos dados sobre a procedência regional ou nacional dos mesmos, abrangência de assuntos, e ano de edição do $1^{\circ}$ fascículo.

\section{Palavras-chave:}

Artes - Pesquisa; Periódicos - Artes; CCN

\section{IDENTIFICATION OF ARTS SERIALS IN BRAZILIAN INSTITUTIONAL LIBRARIES}

\begin{abstract}
:
There is a possible interest in knowing about specialized serials in arts, both in the scope of study and research and in a simple search of information about arts. With the purpose of identify them it was developed a search using as source of information the Brazilian Union Catalog of Serials - CCN. As a result of the study, it is presented a list of serials in Portuguese, Spanish, English, French, Italian, German and Dutch, which has one or more issue edited in 2000 and/or following years, in the collection of the libraries, which feed the system. Besides the serials titles and respective ISSN, it is provided data about the regional or national origin of them, subject scope and year of publication of the first issue.
\end{abstract}

Keywords:

Arts - Research; Arts serials; CCN 


\section{INTRODUÇÃO}

Possivelmente seja de interesse geral, por abranger o âmbito acadêmico, aos de profissionais de artes plásticas e apreciadores das mesmas, saber da existência e diversidade de periódicos que contemplam temas desse campo. Assim, apresenta-se nesse texto, o resultado de uma pesquisa que foi realizada com a finalidade de identificar fontes de informação sobre artes plásticas, mas que, no final, apresentou resultados referentes às artes em geral, visto que muitas dessas fontes têm múltipla focalização. Essa abrangência às artes em geral é, por outro lado, pertinente, visto à interdisciplinaridade hoje assimilada pelas artes plásticas.

Embora o periódico científico tenha sido criado em 1665 (MIRANDA, 1996, p. 376) este se apresenta, ainda hoje, como veículo adequado à propagação de informações referentes aos diversos campos do conhecimento. Assim, de acordo com Targino e Garcia (2000, p. 103), "na atualidade o periódico impresso ainda é um dos canais mais utilizados na comunicação dos resultados de pesquisa". Em que pese a existência de meios eletrônicos que representam, nos dias de hoje, notável possibilidade de acesso à informação, questões como as referentes ao processamento das mesmas devem ser consideradas. Assim, em contraste com a relativa facilidade de lançamento de textos em ambiente $w e b$, tem-se, em geral, para as matérias apresentadas em periódicos impressos, sua prévia submissão a crivos editoriais e de qualidade. Assim, também, a possível alteração, e permanência não garantida de um texto em meio eletrônico, contrasta com a imutabilidade e permanência de uma informação, enquanto registrada em periódico impresso. Por outro lado, tem-se hoje a possibilidade de acesso online a textos transcritos de periódicos impressos. Analisando este aspecto, e relacionando-o com outras questões, Targino e Garcia (2000, p. 114) concluem que haverá ainda, por algum tempo, "coexistência pacífica" entre periódicos impressos e eletrônicos, assim como de réplicas eletrônicas de versões impressas.

Há ainda que considerar a importância representada pelos periódicos (revistas, anais, etc.) quanto à contemporaneidade de assuntos que possam apresentar em relação a questões ou eventos recentes, vantagem não apresentada por compêndios, como os didáticos, em razão da defasagem que estes apresentam como conseqüência de seu processo de elaboração e editoração. 
Assim, o presente estudo tem como objetivo principal identificar os periódicos de arte que possuem edições a partir do ano 2000, existentes em acervos de bibliotecas nacionais, e que sejam editados em português, espanhol, inglês, francês, italiano, alemão e holandês, disponibilizando dados que facilitem sua busca em meio físico ou eletrônico.

\section{PROCEDIMENTOS}

Trata-se de um estudo exploratório-descritivo, de cunho informativo. Foi executado levando em conta aspectos referidos por Lopes (2002) relativos à estratégia de busca e recuperação de registros em sistemas de informação, particularmente quanto à definição dos parâmetros pertinentes à busca (natureza do objeto de estudo e relações temáticas, temporais, geográficas e idiomáticas) e seleção da base de dados em função da disponibilização de campos de busca abrangentes aos mesmos, assim como operacionalização adequada aos objetivos da pesquisa. Desse modo, foi utilizado como fonte de informação o Catálogo Coletivo de Publicações Seriadas - CCN, do Instituto Brasileiro de Informação em Ciência e Tecnologia - IBICT, o qual reúne informações fornecidas por centenas de bibliotecas existentes no país. Por acesso à página eletrônica desse catálogo (IBICT) e busca, por campos, para o assunto "artes" foram levantadas listas de títulos de periódicos, considerando os idiomas de ocorrência das matérias. Em seqüência, foi estendida a busca para registros detalhados, diante dos quais foram selecionados os títulos que apresentassem edição de algum fascículo no ano 2000 e/ou anos seguintes, e presença, pelo menos, em uma das coleções de bibliotecas informantes. Foram também compilados os registros referentes ao ISSN, à procedência regional ou nacional, aos campos temáticos abrangidos pelos mesmos e ao primeiro ano de edição de cada periódico (antigüidade). Com o conjunto de dados assim obtidos foi composto o quadro de resultados adiante apresentado.

\section{RESULTADOS}

Da lista de 542 títulos de periódicos de artes, a qual inclui periódicos vigentes, assim como os que não são mais editados, mas existentes em bibliotecas nacionais, foram identificados 107 referentes ao idioma português, 56 ao espanhol, 212 ao inglês, 105 ao francês, 60 ao italiano, 32 ao alemão e 7 ao holandês. O total destes títulos excede ao total geral em razão de que 
alguns periódicos, que tiveram sua denominação modificada em alguma época, têm, por isso, mais de um registro no catálogo. Noutros casos, como se pode verificar no quadro adiante apresentado, alguns periódicos encontram-se incluídos em mais de uma lista de idioma, em razão da possibilidade de apresentarem matérias naquelas línguas.

Sendo interesse principal dessa pesquisa identificar os periódicos em relação aos quais há existência de fascículos editados no ano 2000 e/ou anos seguintes, apresenta-se, adiante, o quadro em que constam apenas os títulos correspondentes a esse período. Neste quadro, além da denominação de cada periódico, são informados os registros referentes ao respectivo ISSN, a sua procedência regional ou nacional, assuntos que abordam e o ano correspondente ao primeiro fascículo editado.

QUADRO: PERIÓDICOS DE ARTES, COM EDIÇÕES COMPREENDIDAS ENTRE OS ANOS 2000 E 2004 , EDITADOS NOS IDIOMAS PORTUGÊS, ESPANHOL, INGLÊS, FRANCÊS, ITALIANO, ALEMÃO E HOLANDÊS EXISTENTES EM ACERVO DE BIBLIOTECAS INSTITUCIONAIS BRASILEIRAS.

\begin{tabular}{ll|l}
\hline TÍTULO POR IDIOMA & ISSN & $\begin{array}{l}\text { LOCAL DE } \\
\text { EDITORAÇÃ } \\
\text { O ASSUNTO }\end{array}$ \\
\hline
\end{tabular}

\begin{tabular}{|c|c|c|c|c|}
\hline RTUGUÊS & & & & \\
\hline $\begin{array}{l}\text { Anais do Seminário Nacional de Arte e } \\
\text { Educação }\end{array}$ & $1518-4749$ & $\mathrm{RS}$ & artes, educação & 2000 \\
\hline Analecta & $1518-6520$ & PR & $\begin{array}{l}\text { artes, ciências sociais e humanas, } \\
\text { letras }\end{array}$ & 2000 \\
\hline Artcultura & $1516-8603$ & MG & artes, cultura & 1999 \\
\hline Arte e Cultura da América Latina & 0103-8508 & SP & artes, América Latina & 1990 \\
\hline Arteunesp & $0102-6550$ & SP & artes & 1986 \\
\hline Artexto & 0102-2709 & RS & artes, literatura & 1984 \\
\hline Boletim do Museu Carlos Costa Pinto & $0100-4646$ & BA & artes plásticas & 1976 \\
\hline Cadernos da Pós-Graduação & $1516-0793$ & SP & artes & 1997 \\
\hline Cadernos de Pós-Graduação em & $1519-776 \mathrm{X}$ & SP & artes, cultura, educação & 2001 \\
\hline $\begin{array}{l}\text { Educação, Arte e História da Cultura } \\
\text { Contato: Revista Brasileira de }\end{array}$ & $1516-070 X$ & DF & artes, comunicação social, & 1998 \\
\hline $\begin{array}{l}\text { Comunicação, Arte e Educação } \\
\text { Coyote: Revista de Literatura e Arte }\end{array}$ & $1677-5023$ & PR & $\begin{array}{l}\text { educação, relações sociais. } \\
\text { artes, literatura }\end{array}$ & 2002 \\
\hline Educação Gráfica & $1414-3895$ & SP & artes gráficas & 1997 \\
\hline Expressão (Santa Maria) & $1516-9340$ & $\mathrm{RS}$ & $\begin{array}{l}\text { arte dramática, artes-design, artes } \\
\text { plásticas, música-letras }\end{array}$ & 1997 \\
\hline Gráfica (Curitiba) & 0103-3468 & PR & artes plásticas & 1983 \\
\hline Imagem Brasileira & $1519-6283$ & MG & arte sacra, artes & 2001 \\
\hline Imaginário & 1413-666X & SP & $\begin{array}{l}\text { antropologia, artes, geografia, } \\
\text { psicologia }\end{array}$ & 1993 \\
\hline $\mathrm{Jl}$ : Jornal de Letras, Artes e Idéias & $0870-452 X$ & Portugal & artes, letras & 1981 \\
\hline Marco (São Paulo) & 0101-8116 & $\mathrm{SP}$ & artes, conhecimento & 1979 \\
\hline Olhar & $1517-0845$ & SP & artes, humanidades & 1999 \\
\hline Porto Arte & 0103-7269 & PR & artes & 1990 \\
\hline $\begin{array}{l}\text { Revista Mackenzie: Educação, Arte e } \\
\text { História da Cultura }\end{array}$ & $1519-9657$ & SP & artes, cultura, educação & 2001 \\
\hline Revista Arte Comunicação & si & $\mathrm{PE}$ & $\begin{array}{l}\text { artes, comunicação social, } \\
\text { literatura }\end{array}$ & 1994 \\
\hline Revista d' Art & $1415-2231$ & SP & artes & 1997 \\
\hline $\begin{array}{lllll}\text { Revista de } & \text { História } & \text { da } & \text { Arte } & \text { e } \\
\text { Arqueologia } & & & & \end{array}$ & $1413-0874$ & SP & arqueologia, artes & 1994 \\
\hline Revista Universa - Ciências Humanas, & $1677-0315$ & DF & artes, ciências sociais e humanas, & 2002 \\
\hline
\end{tabular}


Letras e Artes

Telas e Artes

Ventura

Veredas (Rio de Janeiro) si

0103-300X

1413-7941

\section{ESPANHOL}

Anales de Historia del Arte

Ariel (Ed. Espanhola): Revista

Trimestral de Artes y Ciencias de Israel

Boletín del Museo Chileno de Arte

Precolombino

Conservación

Galería Anticuaria

Goya: Revista de Arte

Guadalimar

Intersticios: Filosofía, Arte, Religión

Koreana: El Arte y la Cultura de Corea

Kulturchronic

Lápiz

Mundaiz

$0214-6452$

0334-4967

0716-1530

si

1130-2747

$0017-2715$

0210-1254

$1405-4752$

1225-4606

0724-343X

0212-1700

0213-3040

Reseña de Literatura, Arte y 0080-1763

Espectáculos

Review (Latin American Literature and Arts)

0890-5762

\section{INGLÊS}

American Craft
American Journal of Art Therapy
American String Teacher
Antike Kunst
Apollo (London): The Internationa
Magazine of the Arts
Art Bulletin
Art Education
Art History
Art in America
Art Index

Art Journal

Art Libraries Journal

Art News

Art Now Gallery Guide

Art on Paper

Arte Lombarda

Artexto

0194-8008

0007-4764

0003-1313

0003-6536

0004-3079

0004-3125

0141-6790

0004-3214

0004-3222

0004-3249

0307-4722

si

1059-7689

1521-7922

0004-3443

0102-2709

Artforum

0004-3532

Arts and Activities

0004-3931

Bookforum

1098-3376

British Journal of Aesthetics

Bulletin / Council for Research in Music

0007-0904
0003-5688

MG

RJ

$\mathrm{RJ}$

letras

artes

1997

1987

1996

Espanha

Israel

artes, história da arte

1989

artes

1962

Chile

artes

1986

Estados Unidos artes, preservação (arte)

da América

Espanha

Espanha

Espanha

México

Coréia

Alemanha

Espanha

Espanha

artes

artes, trabalhos artísticos

1989

1954

1975

1994

1987

1983

1982

história, lingüística, literatura

Espanha

artes

1964

Estados Unidos artes, cultura, literatura

da América

1968

Estados Unidos artes, artesanato

da América

Estados Unidos artes plásticas, educação

1961

da América

Estados Unidos artes, música

1951

America

Suíça artes 1958

Grã-Bretanha

artes

1925

Estados Unidos artes

1913

da América

Estados Unidos artes

1948

da America

Grã-Bretanha artes 1978

Estados Unidos artes 1913

da América

Estados Unidos artes

da América

Estados Unidos artes 1960

da América

Grã-Bretanha artes, bibliotecas 1976

Estados Unidos artes 1902

da América

Estados Unidos artes, exposições 1988

da América

Estados Unidos artes, artes gráficas, desenho 1998

da América (arte), fotografia artística

Itália artes, história 1955

Brasil artes, literatura 1984

Estados Unidos artes 1962

da América

Estados Unidos artes, educação 1955

da América

Estados Unidos artes

1994

da América

Grã-Bretanha artes, estética 1960

Estados Unidos artes, música 1963 


\section{Education}

Bulletin / Metropolitan Museum of Art

Burlington Magazine

Ceramic Arts \& Crafts

Cinema Technology

Communication Arts Magazine

Conservation (English-Language Ed.)

Crafts

Critical Inquiry

Current Contents. Arts and Humanities

Didactica Classica Gandensia

Flash Art (Ed. Italiana)

Gráfica (Curitiba)

Graphics World

Graphis: The International of Design

and Communication

Hitotsubashi Journal of Arts and

Sciences

Idea: International Graphic Art = Aidea

Journal of Memory and Language

Journal of the American Institute for

Conservation

Journal of the Canadian Association for

Conservation

Journal of the Warburg and Courtauld

Institutes

Kulturchronic

Leonardo: Journal of the International

Society for the Arts Sciences and Technology

Leonardo Music Journal

Museum Studies (Chicago)

Novum (Munchen. 1996)

Poetics (Amsterdam): Journal for

Empirical Research on Literature, the

Media and the Arts

Print: A Quarterly Journal of the

Graphic Art

Print Quarterly

0265-8305

Print Solutions

1535-9727

Puppetry Journal

$0033-443 X$

Ra Magazine

Review (Latin American Literature and

Arts)

Studies En Latin American Popular

Culture

Scholastic Art

School Arts

Sculpture

Sculpture Review

0956-9332

0890-5762

0730-9139

$1060-832 X$

0036-6463

0889-728X

$0747-5284$

South Atlantic Quarterly

0038-2876 da América

Estados Unidos artes

1942

da América

Grã-Bretanha artes 1903

Estados Unidos artes, cerâmica (arte) 1955

da América

Grã-Bretanha arte cinematográfica, artes $\quad 1987$

Estados Unidos artes 1969

da América

Estados Unidos artes, preservação (arte), 1991

da América restauração (arte)

Grã-Bretanha artes plásticas 1973

Estados Unidos artes, crítica de arte 1974

da América

Estados Unidos artes 1979

da América

Bélgica artes 1962

Itália artes 1967

Brasil artes plásticas 1983

Grã-Bretanha artes gráficas 1977

Suíça artes, comunicação visual, 1944

$\begin{array}{lll} & \text { propaganda } & 1960\end{array}$

Japão artes, artes gráficas, propaganda 1953

Estados Unidos artes, ciência, lingüística, religião 1985

da América

Estados Unidos artes, preservação (arte) 1977

da América

Canadá

artes, preservação (arte), 1997

restauração (arte)

não consta

artes, ciência, cultura, religião

Alemanha

artes

1983

artes, ciência, tecnologia $\quad 1966$

Grã-Bretanha

Grã-Bretanha $\quad$ artes, música 1991

Estados Unidos artes 1966

da América

Alemanha

artes

1996

1975

Holanda

artes, literatura

1940

Estados Unidos artes

América

Grã-Bretanha arte, história da arte 1984

Estados Unidos artes gráficas, impressão 2001

da América

Estados Unidos arte dramática, artes

1949

da América

Grã-Bretanha artes 1983

Estados Unidos artes, cultura, literatura 1968

da América

Estados Unidos arte cinematográfica, artes, 1982

da América literatura, música

Estados Unidos artes, artes plásticas 1992

da América

Estados Unidos artes

1901

da América

Estados Unidos artes, escultura

1987

da América

Estados Unidos artes, escultura 1982

da América

Estados Unidos artes, humanidades, literatura, 1902 da América política 
Spazio e Societa $=$ Space \& Society Step-By-Step Graphics

Studies in Art Education

Studies in Conservation $=$ Etudes de Conservation

Studio Potter

The Artist

Transactions of the Connecticut

Academy of Arts and Sciences

Ventura

\section{FRANCÊS}

Art et Decoration

Art Press

Arte Lombarda

Bulletin / Institut Royal du Patrimoine

Artistique $=$ Bulletin Van Het Instituut

Voor Het Kunstpatrimonium

Cimaise

Connaissance des Arts

Flash Art (Ed. Italiana)

Graphis: The International of Design and Communication

Histoire de l' Art

Kulturchronic

L' Oeil : Revue Internationale d' Art

La Part de l' Oeil

Melanges de l' Ecole Française de Rome

. Antiquite

Memoires de la Classe des Sciences de

1' Academie Royale de Belgique.

Collection in 8

Poetics (Amsterdam): Journal for

Empirical Research on Literature, the

Media and the Arts

Revue d Esthetique

Revue de l' Art

Revue de Louvre et des Muses de

France

Studies in Conservation $=$ Etudes de

Conservation

Theatre/Public

Trafic

\section{ITALIANO}

Arte Lombarda

Atti della Accademia Roveretana Degli

Agiati

Bollettino d' Arte

Erba d' Arno

Fmr (Ed. Italiana)

Faenza

Flash Art (Ed. Italiana)

Graphicus

Melanges de l' Ecole Française de

Rome. Antiquite

Mitteilungen des Kunsthistorischen

Institutes Florenz

Nuova Antologia: Rivista di Lettere,

Scienze Ed Arti

Paragone: Mensile di Arte Figurativa e

Letteratura

Prospettiva: A Rivista di Storia dell'Arte
0392-4947

0886-7682

0039-3541

0039-3630

0091-6641

0004-3877

0069-8989

0103-300X

$0245-5676$

0004-3443

0085-1892

0009-6830

0293-9274

0015-3524

0017-3452

0992-2059

0724-343X

0029-862X

0773-9532

0223-5102

0365-0936

$0304-422 X$

0035-2292

0035-1326

0035-2608

0039-3630

0335-2927

1167-2846

0004-3443

0365-0081

0394-4573

0394-5618

0393-0033

0014-679X

0015-3524

0017-3436

0223-5102

0342-1201

0029-6147

0031-1650

0394-0802
Itália

artes, arquitetura

975

Estados Unidos artes, propaganda, publicidade

1985

da América

Estados Unidos artes, educação artística

da América

Grã-Bretanha

artes, restauração

(arte), 1952

Estados Unidos ar

da América

Grã-Bretanha artes

Estados Unidos artes

da América

RJ

artes

1972

1931

1866

1987

\section{França \\ França \\ Itália}

Bélgica

França

França

Itália

Suíça

França

Alemanha

Suíça

Bélgica

Itália

Bélgica

artes, decoração de interiores

1897

1972

1955

1958

artes, patrimônio cultural

1953

1952

$\begin{array}{llll}\text { artes } & & 1967 \\ \text { artes, comunicação } \quad \text { visual, } & 1944\end{array}$

propaganda

artes, historiografia 1988

artes 1983

artes 1955

artes 1985

artes, Europa, história 1971

artes, lingüística

1904

artes, literatura

1975

Holanda

França

França

artes

1948

França

artes

1968

1961

Grã-Bretanha

artes, preservação

(arte), 1952

França

França

arte dramática, artes

1974

1991

Itália

Itália

artes, história

1955

Itália

Itália

Itália

Itália

Itália

Itália

Itália

artes, religião e ciências

1913

$\begin{array}{ll}\text { artes } & 1948 \\ \text { artes, Itália, literatura } & 1980\end{array}$

artes 1982

artes, cerâmica (arte) 1913

artes 1967

artes 1911

artes, Europa, história $\quad 1971$

Alemanha

artes

1908

Itália

artes, ciência, letras

1927

Itália

artes, literatura

1950

Itália

artes

1975 
Antica e Moderna

Spazio e Societa $=$ Space $\&$ Society

0392-4947 Itália

arquitetura, artes

1975

Storia dell' Arte (Firenze)

0392-4513

Itália

arquitetura, artes

1969

\section{ALEMÃO}

Flash Art (Ed. Italiana)

Graphis : The International of Design

and Communication

$0015-3524$

Itália

artes

0017-3452 Suíça

Kulturchronic

Mitteilungen des Kunsthistorischen

Institutes Florenz

0724-343X

0342-1201

Alemanha

artes,

1944

propaganda

Alemanha

artes

1983

$0028-3347$

Alemanha

artes

1908

Neue Rundschau

HOLANDÊS

Bulletin / Institut Royal du Patrimoine Artistique $=$ Bulletin van Het Instituut

Voor Het Kunstpatrimonium

Poetics (Amsterdam): Journal for

Empirical Research on Literature, the 0304-422X

Bélgica

artes, patrimônio cultural

Media and the Arts

si - sem informação

\section{CONSIDERAÇÕES}

Embora o Catálogo Coletivo Nacional de Publicações Seriadas seja fonte de informação utilizada em trabalhos de análise sobre diversos aspectos relativos a periódicos, tais como o de Krzyzanowski e Ferreira (1998) que levanta dados sobre a regularidade, periodicidade e distribuição de revistas científicas nacionais, devem ser consideradas possíveis limitações quanto à totalidade do universo aqui retratado. Tendo em vista que o sistema de formulação do catálogo é alimentado por informações fornecidas espontaneamente por bibliotecas institucionais brasileiras, é possível que periódicos de circulação mais restrita não tenham sido alcançados por essa consulta.

Considerando a possível existência de interstícios variáveis quanto ao tempo de entrada de um fascículo no acervo de uma biblioteca e o aparecimento dessa informação no catálogo, além do fato, apontado por Targino e Garcia (2000, p. 113), de que são necessários 5 anos para que um periódico novo se firme em sua especialidade, foi considerado apropriado fazer o recorte de identificação corresponder ao ano 2000.

Optou-se, também, por fazer uma distribuição dos periódicos por idioma, caso seja este fator de preferência ou restrição de interesse do leitor. Entretanto, o conjunto de títulos, assim abrangidos, constitui a quase totalidade dos periódicos com presença no referido catálogo. 
Foi feita a inclusão, no quadro de resultados, do ano correspondente ao primeiro fascículo editado, no intuito de permitir uma idéia sobre a antiguidade ou sua consolidação como veículo de comunicação.

Com relação a esse aspecto, é de se notar, sobre aqueles periódicos em português que têm fascículos editados após o ano 2000, um surgimento, de modo geral, mais recente que os de outras procedências. Possivelmente, isso reflita dificuldade quanto a sobrevivência das revistas brasileiras mais antigas. Sendo este o caso, conveniente seria, que apoios fossem destinados no sentido de fortalecer não só as revistas que se mantêm presentes como aquelas que estejam em processo de implantação. Outra caracterização dos periódicos brasileiros, que parece lastimável, refere-se ao fato de que os 27 que compõe a lista provém de apenas 8 Estados da Federação, correspondendo a uma produção editorial de 13 títulos na região sudeste, 7 na região sul, 5 na região centro-oeste e 2 no nordeste.

Tal quadro parece refletir a necessidade de implementar maior vigor, seja na produção, seja na atribuição de visibilidade aos periódicos nacionais, pois é através desse processo que se poderá também conferir maior difusão do que está sendo produzido no âmbito das artes no Brasil, fato que interessa não só aos seus autores como também aos próprios editores e ao público da área.

\section{REFERÊNCIAS}

IBICT. Instituto Brasileiro de Informação em Ciências e Tecnologia. Consulta ao CCN. Disponível em: $<$ http://www.ct.ibict.br:82/ccn/owa/ccn_consulta $>$. Acesso em: 10 jun. 2004.

KRZYZANOWSKI, R. F.; FERREIRA, M. C. Avaliação de periódicos científicos e técnicos brasileiros. Ci. Inf., v. 27, n. 2, p. 165-175, 1998.

LOPES, I. L. Estratégia de busca na recuperação da informação: revisão da literatura. Ci. Inf., v. 31, n. 2, p. 60-71, 2002.

MIRANDA, D. B. O periódico científico como veículo de comunicação: uma revisão de literatura. Ci. Inf., v. 25, n. 3, p.375-382, 1996.

TARGINO, M. G.; GARCIA, J. C. R. Ciência brasileira na base de dados do Instituto for Scientific Information (ISI). Ci. Inf., v. 29, n. 1, p. 103-117, 2000. 


\section{Viviane Rummler da Silva}

Graduada em Artes Plásticas pela Universidade Federal da Bahia - UFBa.

E-mail: virummler@ig.com.br

\section{Prof. Dr. Guido Rummler}

Professor titular de Metodologia da Pesquisa, Universidade Estadual de Feira de Santana - UEFS.

E-mail: rummler@ufba.br.

Artigo aceito para publicação em: 12/2004 